\title{
Impact of damper opening time on work of storage matrix regenerative heat exchanger
}

\author{
Maciej Skrzycki ${ }^{1, *}$, and Maciej Besler ${ }^{1}$ \\ ${ }^{1}$ Department of Air Conditioning, Heating, Natural Gas Engineering and Air Protection, Faculty \\ of Environmental Engineering, Wroclaw University of Technology, Wyb. Wyspianskiego 27, \\ 50-370 Wroclaw, Poland
}

\begin{abstract}
Devices that by heat exchange take heat from exhaust air stream and transfer it to the external air stream in order to pre heat are called heat recovery heat exchangers. The heat exchange may take place through the wall (diaphragm) or using heat storage liquid (these devices are called recuperators) or by direct contact of exhaust and external air stream with the heat transfer surface - these devices are called regenerators. The publication presents the work characteristics of the storage matrix heat exchanger based on laboratory tests. In order to achieve the objectives the research station was designed and built.
\end{abstract}

\section{Introduction}

Currently in Poland described heat exchanger is not very well known and widely used, even though its construction was known and developed long before the rotary heat exchanger. This heat exchanger is an attractive alternative to other heat exchangers, both recuperators and regenerators. The purpose of this article is a closer representation of the storage matrix heat exchanger, its construction, high efficiency, but occasionally reported in the literature.

The storage matrix heat exchangers are often also called accumulative heat exchangers or reversible heat exchangers and operate on the principle of alternating washing out of accumulative storage matrixes within a specified period of time by an exhaust air stream and external air stream [1]. Air distribution through the chambers of storage blocks is arranged by using dampers, mechanically coupled with each other. The following is a flowchart of storage matrix heat exchanger.

The exchanger consists of two independent storage blocks and a dampers system with actuators for changing the direction of air flow. Storage matrix is similar to the matrix used in rotary heat exchangers. The main difference lies in the layered arrangement of plates and the undulating arrangement between the layers of sheets of metal. Storage matrix chambers are separated from each other by a vertical partition. After a predetermined time, the air flow is reversed by dampers. As a result of matrix temperature difference and air stream temperature, outlet air stream temperatures changes. Time of one cycle of air flow through the storage matrix chambers are variable and depend on the manufacturer of approx.

*Corresponding author: maciej.skrzycki@pwr.edu.pl 
20 seconds [2] to even 100 seconds [3]. The graph in Fig. 1 shows an operation of storage matrix heat exchanger [4].

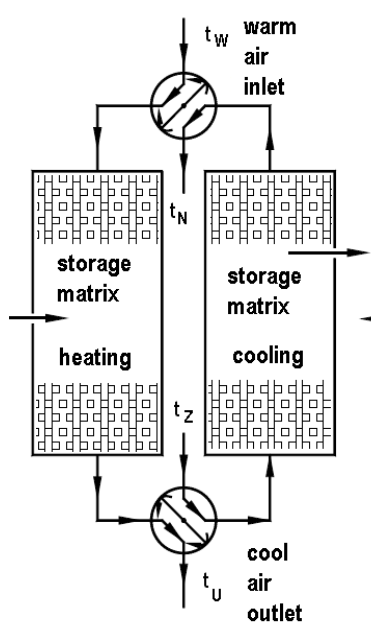

(a)

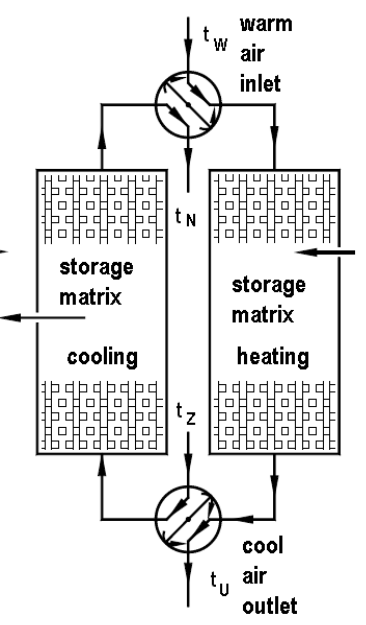

(b)

Fig. 1. Principle of operation of storage matrix heat exchanger: a) charging phase, b) discharging phase [4].

Storage blocks chambers have a responsive mechanism to change the direction of air flow during even less than 1 second [2] - it is shown in Fig. 1 and 2.
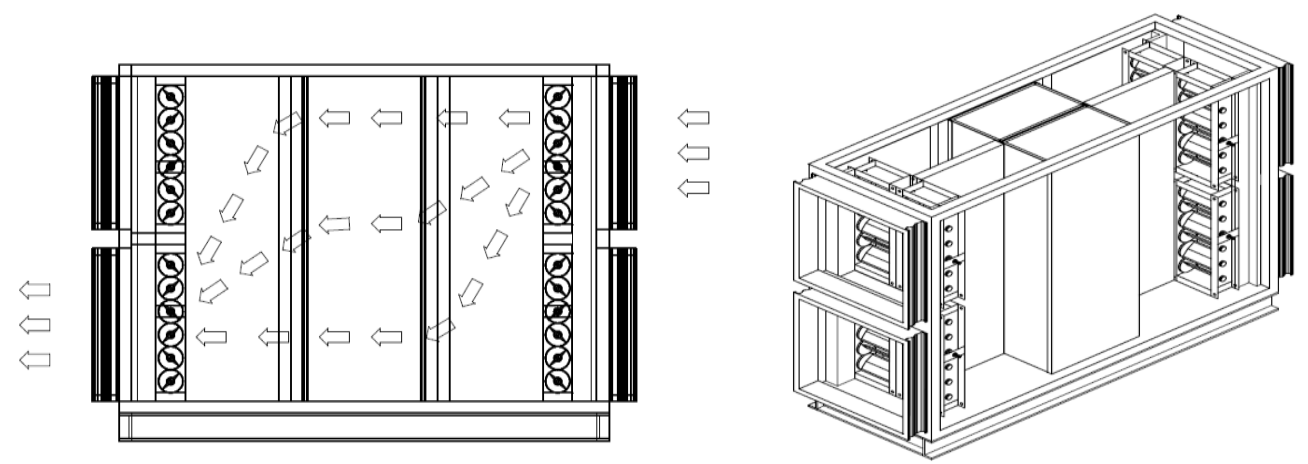

Fig. 2. Airflow through the single heat exchanger chamber in one cycle of work of the device and the three dimensional view of the device (fig. authors).

The average heat flux transferred in a storage matrix heat exchanger can be assumed as follows [5]:

$$
Q^{s r}=\frac{Q_{a k}}{\tau^{o k}}=\bar{\kappa} c \rho V\left(t^{G R Z}-t^{C H}\right)
$$

$Q_{a k}$ - heat accumulated in the matrix of a regenerator, $\mathrm{kW}$

$\tau^{\mathrm{ok}}-$ regenerator cycle, $\mathrm{s}$

$$
\bar{\kappa}=\frac{\vartheta_{s r}^{g}\left(\tau^{G R Z}\right), \vartheta_{s r}^{g}(o)}{t^{G R Z}-t^{C H}} \frac{1}{\tau^{o k}}
$$


$t^{G R Z}, t^{C H}$ - air stream temperatures in the charging and discharging phase, ${ }^{\circ} \mathrm{C}$

$v^{g}{ }_{s r}$ - average matrix temperatures at the end and beginning of charging phase, ${ }^{\circ} \mathrm{C}$

$c, \rho, V$ - specific heat, density, air stream,

$\kappa$ - heat flux reduced in the regenerator, $\mathrm{kW}$

In analogy to the rotary heat exchangers, also in the storage matrix heat exchangers the cycle is split into two equal phases: heat transfer from the air to the matrix and from the matrix to the air. This process (shown in Fig. 3) can be described as $\tau_{0}=\tau_{1}+\tau_{2}$ [5].

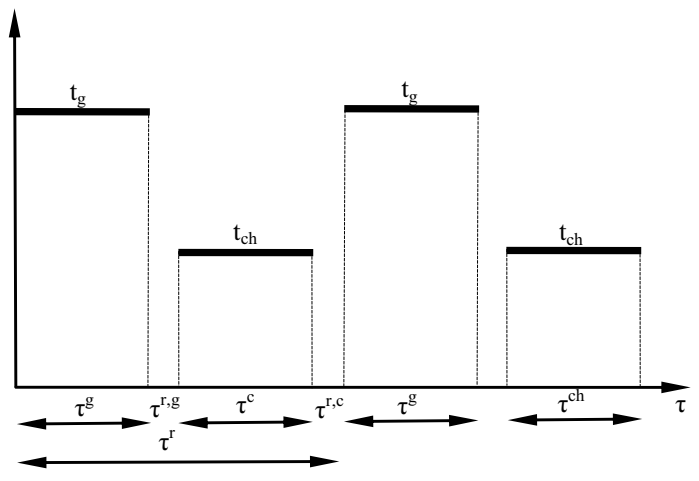

Fig. 3. The temperatures of air streams entering the regenerator in accordance of time: $t_{g}$ - warm air stream temperature, $t_{c h}-c o o l$ air stream temperature, $\tau^{\mathrm{r}}$ - regenerator work time, $\tau^{\mathrm{g}}-$ time of charging phase, $\tau^{\text {ch }}$ - time of discharging phase, $\tau^{\mathrm{r}, \mathrm{g}}-$ reversion time after charging phase, $\tau^{\mathrm{r}, \mathrm{g}}-$ reversion time after discharging phase [5].

The work of storage matrix regenerators is symmetrical - time of flow of warm air stream through a first chamber of heat exchanger is equal to the time of flow of cool air stream through the second chamber of heat exchanger. The sum of these times is the time of cycle of air flow through the heat exchanger [2]. The time needed to change the direction of the flow of air streams is assumed as negligible.

At the time of switching of dampers at the inlet and outlet of heat exchanger the air streams contacts with each other. Accordingly, the use of storage matrix heat exchangers is similar to the rotary heat exchangers and is not recommended if there is an emission of harmful substances, aromatic substances, etc. because of the risk of flow of these substances in the heat exchanger to the external air stream [2].

Storage matrix heat exchangers respective to the flow of the air streams can be compared to the counterflow heat exchangers. In the heat exchanger cross-section the temperature fluctuations are recurrent in each cycle of work of exchanger - in charging and discharging phase [6]. These temperatures decrease along with decreasing of cycle time or the length of the air flow in the heat exchanger, as well as with the change of the heat capacity of the storage matrix.

\section{Research station and description of tests}

Tests were performed on storage matrix heat exchanger type BA-19-500-0600x1350-VG1. The main element is storage matrix made of aluminum plates having a thickness of $0,1 \mathrm{~mm}$ placed at a distance of $2,0 \mathrm{~mm}$ from each other, between which are placed further layers of corrugated sheets of aluminum. The matrix length is $500 \mathrm{~mm}$ and it is placed in housing with $585 \mathrm{~mm}$ width and $1350 \mathrm{~mm}$ height (Fig. 5). In each duct in the inlet and in the outlet are arranged two dampers (total 8 dampers), each other connected with the actuators. 
Fig. 4 shows the appearance of the tested heat exchanger at the research station and Fig. 5 shows the constructional dimensions of the tested heat exchanger.
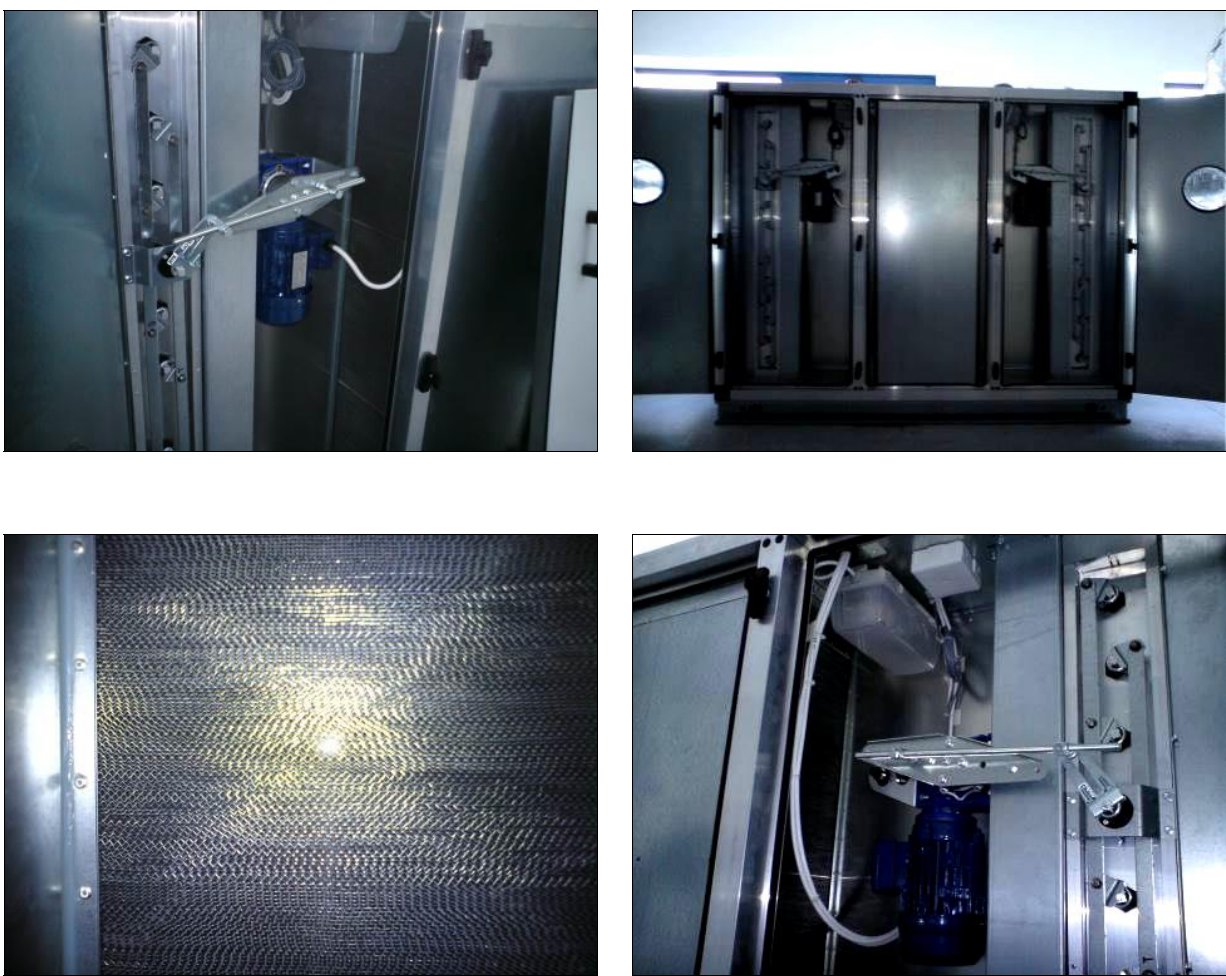

Fig. 4. Construction of storage matrix heat exchanger (photog. authors).
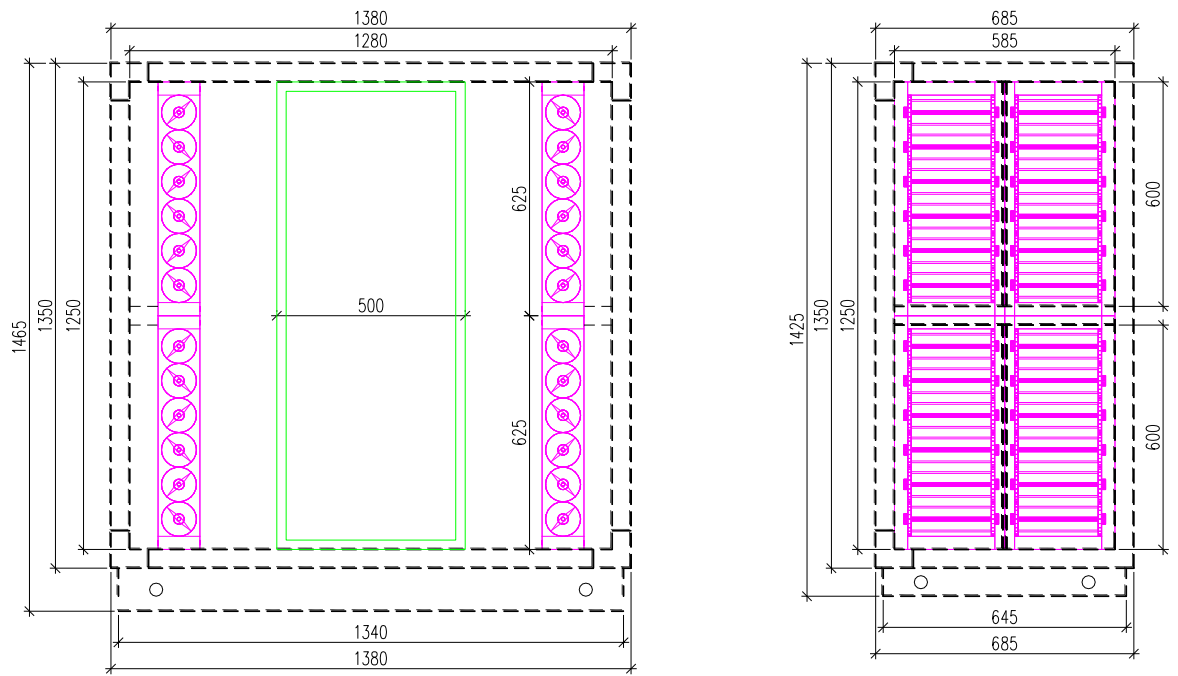

Fig. 5. The constructional dimensions of the tested heat exchanger (fig. authors). 
Air flow value was determined at $\mathrm{V}=1200 \mathrm{~m}^{3} / \mathrm{h}$. The variable value was the air flow through the matrix chambers of heat exchanger. The initial period of air flow was set at 30 seconds with 30 second step of damper opening/close time. During the measurements exhaust air temperature was taken, as a constant value throughout the measurement period at $\mathrm{t}_{\mathrm{w}}=25^{\circ} \mathrm{C} \pm 1,0^{\circ} \mathrm{C}$.

The following charts show the results of measurements of efficiency of the tested heat exchanger (Fig. 6 and Fig. 8), and the temperature of the air streams (Fig. 7 and Fig. 9).

The temperature measurements were based on the guidelines in the standard [7], the air flow measurements were based on the guidelines in the standard [8].

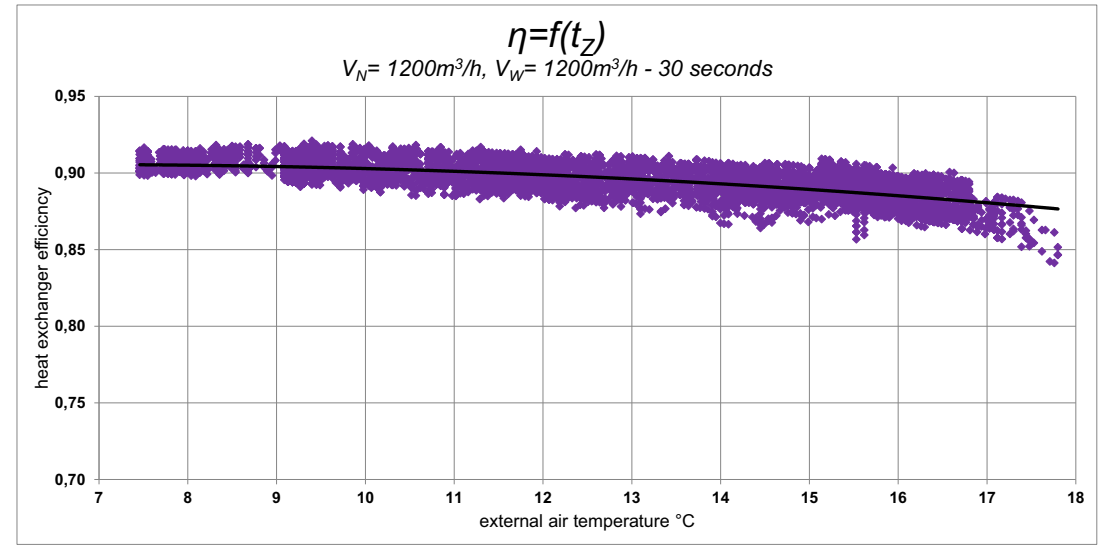

Fig. 6. Efficiency chart of tested heat exchanger in an exemplary measurement period by 30 -second airflow through the storage matrix chambers.

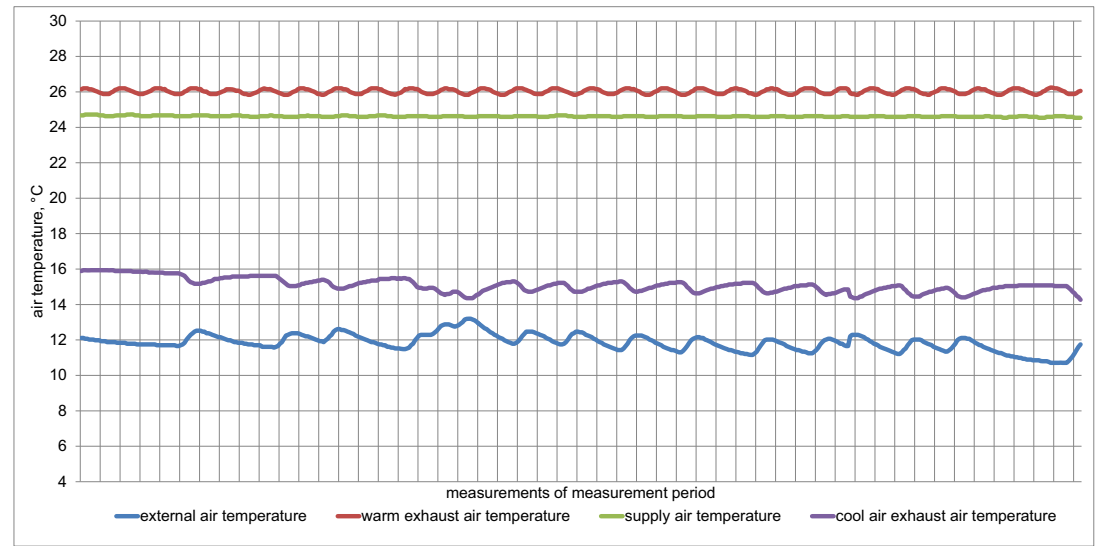

Fig. 7. Chart of variability of air temperatures of tested heat exchanger in an exemplary measurement period by 30 -second airflow through the storage matrix chambers. 


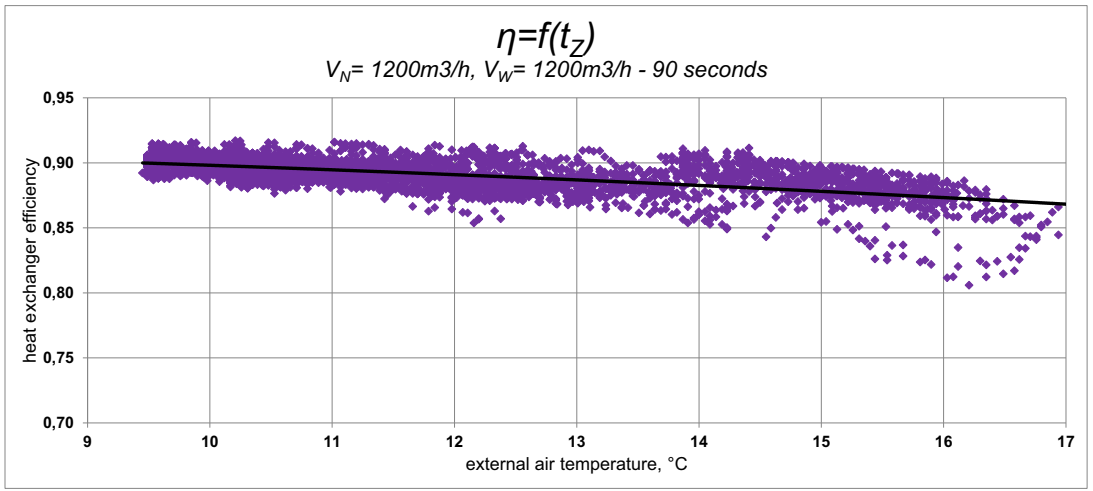

Fig. 8. Efficiency chart of tested heat exchanger in an exemplary measurement period by 90 -second airflow through the storage matrix chambers.

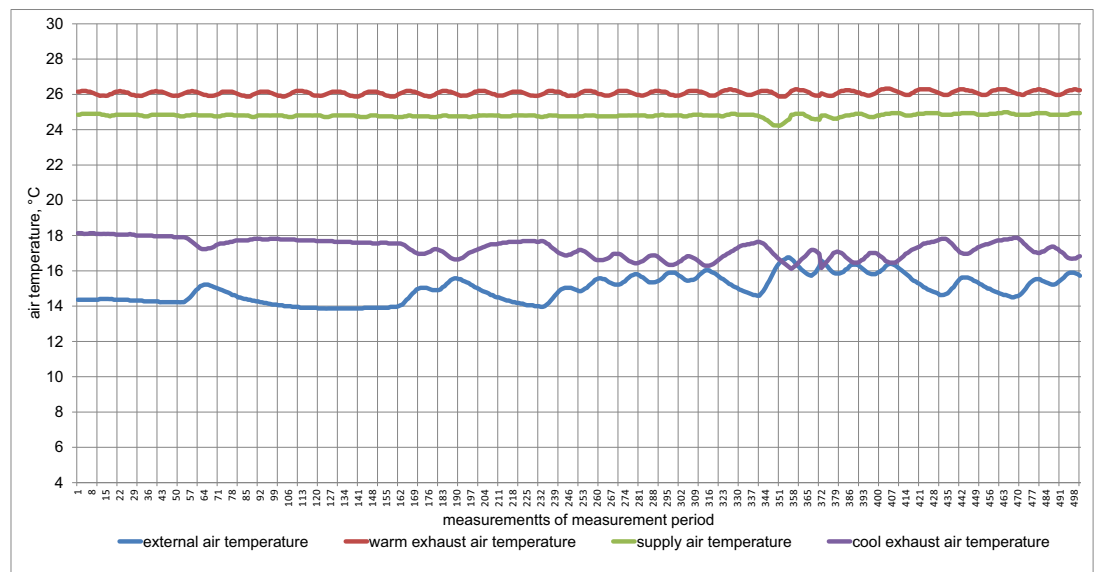

Fig. 9. Chart of variability of air temperatures of tested heat exchanger in an exemplary measurement period by 90 -second airflow through the storage matrix chambers.

\section{Summary}

Regardless to the time between the dampers changeover high coefficient of heat recovery efficiency was achieved. The values obtained the requirements of the current legislations and the measurements confirmed the efficiency of this type of heat exchangers.

As it is shown in the graphs, heat transfer efficiency is higher for low external air temperatures. Longer warm-up time (damper changeover time) of storage matrix by the exhaust air stream will not always result in more energy storage. It is due to the thermal capacity of the storage matrix and heat transfer coefficient which is also dependent on the speed of the stream. For longer periods, the excess of the available energy is not absorbed by the storage matrix. Determination of optimum length of time between the dampers changeover must take into account the air flow velocity and accumulative capacity of the material used.

Considered storage matrix heat exchanger in the measuring period worked with an average efficiency of approx. $90 \%$ over the entire external air temperatures. 


\section{References}

1. T. Kuppan, Heat exchanger design handbook, Marcel Dekker Inc., New York-Basel 2000

2. Fenix air handling unit with Superblok heat exchanger (in Polish), Web page: http://climaprodukt.com/produkt/fenix/

3. Resolair air handling unit (in Polish), Web page: http://www.menerga.pl/produkty,2,centrale-menerga,11,resolair-6264666865,72

4. T. Skiepko, R. K. Shah, Int. J. Heat Mass Tran. 48 (2005) 1608-1632, Web page: http://www.sciencedirect.com/science/article/pii/S0017931004005095

5. E. Kostkowski, Heat flow, Silesian University of Technology Publishing House, 2006 (in Polish)

6. E. Kalinowski, Heat transfer and heat exchangers, Warsaw University of Technology Printing House, Warszawa 1995 (in Polish)

7. PN-EN 308:2001 Heat exchangers. Test procedures for establishing the performance of air to air and flue gases heat recovery devices, Polish Committee for Standardization, Warsaw 2001 (in Polish)

8. PN-ISO 5221 Air distribution and air diffusion -- Rules to methods of measuring air flow rate in an air handling duct, Polish Committee for Standardization, Warsaw 1994 (in Polish) 